\title{
PKM Rumah Baca Kreatif Berbasis E-Learning Upaya Menumbuhkan Budaya Literasi Anak Binaan SD Muhammadiyah 09 Bahari Surabaya
}

\author{
${ }^{1}$ Peni Suharti, ${ }^{2}$ Ruspeni Daesusi, ${ }^{3}$ Ratno Abidin, ${ }^{4}$ Asy'ari \\ 1,2,3\&4 Universitas Muhammadiyah Surabaya, Jl. Sutorejo No. 59 Surabaya, Jawa Timur. \\ Indonesia.
}

Email Korespondensi:peni_suharti@um-surabaya.ac.id

\begin{tabular}{|c|c|}
\hline Article Info & bstract \\
\hline $\begin{array}{l}\text { Article History } \\
\text { Received: } 2020-02-28 \\
\text { Revised: } 2020-06-26 \\
\text { Published: } 2020-06-30\end{array}$ & \multirow{2}{*}{$\begin{array}{l}\text { PKM Creative Reading House Based on E-Learning Efforts to Grow Literacy } \\
\text { Culture of Fostered Children of SD Muhammadiyah } 09 \text { Bahari Surabaya. } \\
\text { The purpose of this PKM activity is to foster a literacy culture of fostered } \\
\text { children at SD Muhammadiyah 09 Bahari Surabaya through e-learning-based } \\
\text { creative reading houses. This activity involved all the teachers at SD } \\
\text { Muhammadiyah 09 Bahari Surabaya. The method used to solve problems } \\
\text { provided by partner teachers through training in IST activities (service } \\
\text { training), OST (service training) and implementation. 1) the implementation of } \\
\text { PkM in accordance with the plan, 2) formed teacher knowledge and } \\
\text { understanding of e-learning learning, 3) the formation of teacher skills in using } \\
\text { e-learning media in learning. Mentoring activities still need to be done so that } \\
\text { the teacher can really make and apply it in learning, and in addition there } \\
\text { needs to be learning to be applied in grades } 1,2 \text { and } 3 \text { elementary schools. } \\
\text { Especially at SD Muhammadiyah } 09 \text { Bahari Surabaya }\end{array}$} \\
\hline $\begin{array}{l}\text { Keywords } \\
\text { Creative reading house } \\
\text { e-learning } \\
\text { children's literacy culture }\end{array}$ & \\
\hline Infor & Abstrak \\
\hline $\begin{array}{l}\text { Diterima: } 28-02-2020 \\
\text { Direvisi: } 26-06-2020 \\
\text { Dipublikasi: } 30-06-2020\end{array}$ & \multirow{2}{*}{$\begin{array}{l}\text { Tujuan kegiatan PKM ini adalah untuk menumbuhkan budaya literasi anak } \\
\text { binaan SD Muhammadiyah } 09 \text { Bahari Surabaya melalui rumah baca kreatif } \\
\text { berbasis e-learning. Kegiatan ini melibatkan semua guru yang ada di SD } \\
\text { Muhammadiyah 09 Bahari Surabaya. Metode yang digunakan untuk } \\
\text { menyelesaikan permasalahan yang dihadapi guru mitra yaitu melalui } \\
\text { serangkaian kegiatan IST (in service training), OST (on service training) dan } \\
\text { implementasi. Hasil kegiatan ini antara lain 1) terlaksananya PKM sesuai } \\
\text { dengan rencana, 2) terbentuknya pengetahuan dan pemahaman guru tentang } \\
\text { pembelRajaran e-learning, 3) terbentuknya keterampilan guru dalam } \\
\text { menggunakan media e-learning dalam pemblajaran. Kegiatan pendampingan } \\
\text { masih perlu dilakukan secara kontinu agar guru benar-benar dapat membuat } \\
\text { dan mengaplikaskannya dalam pembelajaran, selain itu perlu ada inovasi } \\
\text { pembelajaran e learning untuk di terapkan pada kelas } 1,2 \text { dan } 3 \text { SD. Khususnya } \\
\text { di SD Muhammadiyah } 09 \text { Bahari Surabaya }\end{array}$} \\
\hline $\begin{array}{l}\text { Kata kunci } \\
\text { Rumah baca kreatif } \\
\text { e-learning } \\
\text { budaya literasi anak }\end{array}$ & \\
\hline
\end{tabular}

Sitasi: Suharti P., Daesusi R., \& Abidin R. (2020) PKM Rumah Baca Kreatif Berbasis E-Learning Upaya Menumbuhkan Budaya Literasi Anak Binaan SD Muhammadiyah 09 Bahari Surabaya. Sasambo: Jurnal Abdimas (Journal of Community Service). 2(2), 40-48. DOI : 10.36312/sasambo.v2i2.187

\section{PENDAHULUAN}

Peringkat minat baca Indonesia berdasarkan World's Most Literate Nations Ranked tahun 2016 menempatkan Indonesia di peringkat 60 dari 61 negara yang disurvei. Dibandingkan dengan negaranegara tetangga di Asia Tenggara, Indonesia jauh di bawah Singapura yang berada di peringkat 36, diikuti Malaysia dan Thailand yang masing-masing di peringkat 53 dan 59 (Hutapea, 2019). Empat tahun sebelumnya, tahun 2012, UNESCO pernah melansir data mengenai indeks tingkat membaca orang Indonesia yang hanya 0,001 
persen. Artinya, dari 1.000 penduduk hanya terdapat satu orang yang memiliki minat baca (Mansyur, 2019).

Kurangnya minat baca terjadi dari tingkat Sekolah Dasar (SD) hingga perguruan tinggi, kondisi ini diperparah oleh kebiasaan bermain game. Siswati (2010) Kebiasaan bermain game online dan melihat TV mampu menghalangi minat membaca mahasiswa. Pembiasaan anak mengguakan gadget yang hanya cenderung dijadikan media bermain sudah menjadi kebiasaan terutama di kalangan siswa sekolah dasar. Sudah banyak tulisan yang secara langsung mengkritik budaya ini. Namun tulisan hanya sekedar peringatan yang kadang sulit mempengaruhi perubahan mereka, apalagi tidak didukung oleh keluarga terdekat tentu anak-anak akan bebas melalukan apa saja sesuai dengan kemauannya sendiri. Maka dengan seperti itu tentu menjadi permasalahan serius dalam proses perkembangan anak-anak kedepannya. Karena anak merupakan generasi penerus bangsa sehingga harus mampu memberikan yang terbaik kepada perkembangan hidupnya (Ngafifi, 2014)

Kondisi saat ini yang sanagat fenominal di kehidupanan anak-anak adalah maraknya game melalui gadjet masing-masing tanpa peduli dengan kondisi apapun. Apalagi dengan sangat mudahnya sekarang mengakses berbagai permainan sesuai dengan keinginan mereka. Pada era media baru, audiens/pengguna menggunakan media sesuai kemauan pribadinya, makin selektif, menjadi penerima pesan sekaligus pembuatnya. Anak-anak sebagai sebagai pengguna internet juga mengindikasikan tren yang sama, dengan mantap penggunaan internet oleh mereka makin bertumbuh. Kompas.com Asosiasi dokter anak Amerika Serikat dan Kanada menekankan perlunya anak usia 0-2 tahun sama sekali tidak terpapar gadget. Sementara anak 3-5 tahun dibatasi satu jam per hari dan dua jam untuk anak 6-18 tahun. Sehingga hal itu menjadi sangat kruasial untuk menjadi perhatian semua terkait dampak negatif teknologi informasi kepada anak-anak ketika salah menggunakannya

Namun faktanya, anak-anak justru menggunakan gadget 4-5 kali lebih banyak dari jumlah yang direkomendasikan. Bahkan, penggunaan ponsel pintar, tablet, dan peranti game elektronik sudah dimulai sejak usia sangat dini. Dokter anak asal Amerika Serikat Cris Rowan mengatakan, perlu ada larangan untuk penggunaan gadget pada usia terlalu dini, yakni anak di bawah 12 tahun. Alasannya, sudah banyak penelitian yang membuktikan dampak negatif gadget pada mereka. Berikut di antaranya: Pertumbuhan otak yang terlalu cepat, Hambatan perkembangan, Obesitas, Gannguan tidur, Penyakit mental, Agresif, pikun, digital, adikasi dan radiasi. Maka Dalam menyikapi perkembangan zaman teknologi pada saat ini, setiap hendaknya mengetahui waktu yang tepat untuk memberikan gadget pada anak. Selain itu, orangtua juga harus terus berpartisapasi mengangi pertumbuhan dan perkembanagan anak dengan cerdik (Daryanto, 2018).

Membeca adalah jendela dunia, karena dengan membaca manusia dapat mengetahui banyak hal yang tidak diketahuinya. Kemampuan dan kemauan membaca akan mempengaruhi pengetahuan dan keterampilan (skill) anak. Semakin banyak membaca dapat dipastikan seseorang anak akan semakin banyak tahu dan banyak bisa, artinya banyaknya pengetahuan seorang anak akan membantu dirinya dalam melakukan banyak hal yang sebelumnya tidak dikuasainya, sehingga seseorang yang banyak membaca memiliki kualitas yang lebih dari orang yang sedikit membaca (Rosini \& Nurningsih, 2018).

Dalam Undang-undang Nomor 43 Tahun 2007 tentang Perpustakaan pasal 48 ayat 1 dinyatakan bahwa "pembudayaan kegemaran membaca dilakukan melalui keluarga, satuan pendidikan dan masyarakat. Selanjutnya dalam pasal 49 dinyatakan bahwa "pemerintah, sehingga pemerintah daerah dan masyarakat mendorong tumbuhnya Taman Bacaan Masyarakat untuk menunjang pembudayaan kegemaran membaca. Karena degan membaca masyarakat akan berdaya dan berperadaban. Maka disi yang lain diera saat ini membaca tidak harus dengan beli buku yang mahal, namun dengan e-book yang bisa diakses secara sudah bisa di update setiap saat (Hanum, 2013) 
Data BPS lainya juga menunjukkan bahwa penduduk Indonesia belum menjadikan membaca sebagai informasi. Orang lebih memilih televisi dan mendengarkan radio. Malahan kecenderungan cara mendapatkan informasi lewat membaca stagnan sejak 1993. Hanya naik sekitar $0,2 \%$. Jauh jika dibandingkan dengan menonton televisi yang kenaikan persentasenya mencapai 211,1\%. Data 2009 menunjukkan bahwa orang Indonesia yang membaca untuk mendapatkan informasi baru 23,5\% dari total penduduk (Meliza, Adnan \& Safiah, 2016).

Namun dalam kondisi yang sesungguhnya budaya baca masyarakat masih relatif kurang. Minat baca masyarakat Indonesia masih rendah karena hal ini bisa diperhatikan dari data berikut. Data yang dikeluarkan Badan Pusat Statistik (BPS) pada tahun 2006 dapat dijadikan gambaran bagaimana minat baca bangsa Indonesia. Data itu menggambarkan bahwa penduduk Indonesia berumur di atas 15 tahun yang membaca koran hanya 55,11\%. Masyarakat yang membaca majalah atau tabloid hanya $29,22 \%$, buku cerita $16,72 \%$, buku pelajaran sekolah $44,28 \%$ dan yang membaca buku ilmu pengetahuan lainnya hanya $21,07 \%$ (Aztry, 2016 ).

Oleh karena itu dalam hal penanganan itu hendaknya memberikan batasan pada anak dalam menggunakan gadget sehingga tidak menjadi ketergantungan yang akan memberikan dampak negatif terhadap tumbuh kembangnya. Kemudian juga hal ini tentunya menjadi satu tugas besar bagi sekolah untuk mengatasi masalah kurangnya budaya leterasi bagi anak. Berdasar hasil penelitian. Batasan ini lebih memperjelas pengertian minat tersebut dalam kaitannya dengan perhatian seseorang. Sehingga perkembangan teknologi lebih diarahkan untuk dimanfaatkan bernilai edukasi yaitu memlaui e-learning. berbagai keunggulan yang dimiliki program elerning telah menginspirasi banyak ahli di bidang pendidikan untuk memberdayakannya dalam skala yang lebih luas, sehingga tidak terbatas dalam pembelajaran semata, tapi menjadi piranti utama dalam penyelengaraan pendidikan. Misalnya, munculnya lembaga yang menyelenggarakan pendidikan jarak jauh dan lain sebagainya tanpa harus sulit dengan berkas-berkas seperti yang terjadi pada zaman dulu (Diana, 2018).

Model pendidikan berbasis teknologi informasi dengan menggunakan e-learning berakibat pada perubahan budaya belajar dan membaca dalam kontek pembelajarannya. Setidaknya ada empat komponen penting dalam membangun budaya belajar denganmenggunakan model e-learning di sekolah, keempat komponen itu ialah peserta didik dituntut secara mandiri dalam belajar dengan berbagai pendekatanyang sesuai agar siswa mampu mengarahkan, memotivasi, mengatur dirinyasendiri dalam pembelajaran. Pendidik mampu mengembangkan pengetahuan dan ketrampilan,memfasilitasi dalam pembelajaran, memahami belajar dan hal-hal yang dibutuhkan dalam pembelajaran. Tersedianya infrastruktur yang memadai. Adanya administrator yang kreatif serta penyiapan infrastrukur dalam memfasilitasi pembelajaran (Yazdi, 2012)

Berdasarkan uraian tersebut maka, tim PkM melakukan kegiatan dengan dua tahapan yakni IST (in service training) dan OST (on service training) dengan tujuan untuk menumbuhkan budaya literasi anak binaan SD Muhammadiyah 09 Bahari Surabaya melalui rumah baca kreatif berbasis e-learning.

\section{METODE PELAKSANAAN}

Solusi yang digunakan untuk menyelesaikan permasalahan yang dihadapi guru mitra yaitu dengan menggunakann metode IST (in service training), OST (on service training), dan implementasi untuk memastikan hasil dari kedua kegiatan terlaksana dengan baik. Adapun tahapan dalam kegaitan PkM ini adalah.

1. IST (in service training) meliputi perencanaan seperti;

a. Tahap persiapan. Kegiatan yang dilakukan pada tahapan ini meliputi: menyusun ToR (Term of Reference), identifikasi calon peserta, pertemuan internal tim PkM (seperti penentuan waktu pelatihan, tempat, dan materi), dan pengurusan izin melaksanakan kegiatan pengabdian. 
b. Persiapan alat dan bahan; Tim PKM dan anggota mitra secara bersama-sama mempersiapkan semua bahan dan peralatan yang diperlukan selama pelaksanaan program PKM. Salah satunya adalah Pemasangan Speedy Internet. Sebelum peroses program pkm rumah baca kreatif berbasis e-learning tim pelaksana memasang speedy sebagai alat penunjang untuk kelancara acara pendampingan meimlpementasikan pembelajaran guru-guru dan anak binaan SD Muhammadiyah 9 Bahari Surabaya

a. Menyusun Buku Panduan Pembelajaran E-learning

Tim pelaksana program rumah baca berbasis e-lerning memproses menyusun buku panduan pembelajaran e-learning sekolah dasar yang menjadi acuan untuk proses pembelajaran e-learning di sekolah. Buku panduan ini berisi alur dan mikanisme praktek pembelajaran e-learning dengan beberapa gambar yang menjadi lebih mudah untuk dipahami. Buku yang telah tersusun tim PkM melakukan pengurusan ISBN buku panduan

2. OST (on service training) meliputi Pelaksanaan Program

a. Workshop dan Pelatihan Pembelajaran E-learning, Proses workshop pembelajaran elearning ini akan langsung difalitasi langsung oleh tutor e-learning yang dilaksanakan sesuai dengan jumlah guru dan Siswa binaan SD Muhammadiyh 9 Bahari Surabaya sambil membawa laptop sebagai alat untuk pembelajaran menggunakan e-learning

b. Pendampingan guru dalam mengoprasikan pembelajaran dengan menggunakan $e$ learning

c. Evaluasi

\section{HASIL DAN PEMBAHASAN}

Kegiatan PKM telah dilaksankan di SD Muhammadiyh 9 Bahari Surabaya, dengan tema kegiatan "PKM Rumah Baca Kreatif Berbasis E-Learning Upaya Menumbuhkan Budaya Literasi Anak Binaan SD Muhammadiyah 09 Bahari Surabaya". Kegiatan ini bertujuan untuk menumbuhkan budaya literasi anak binaan SD Muhammadiyah 09 Bahari Surabaya melalui rumah baca kreatif berbasis e-learning. Mitra dalam kegiatan ini adalah guru guru dan siswa SD Muhammadiyah 09 Bahari Surabaya.

1. Melakukan Sosialisasi dan Koordinasi Tim Pelaksana dengan Mitra

Adanya penerapan pembelajaran melalui pembelajaran e-learning dapat melatih para guru dari segi keterampilan dan pemahaman dalam mengoprasikan e-learning para guru dan anak binaan SD Muhammadiyah 9 Bahari Surabaya. Dengan proses pembimbingan pembelajaran eletronik yang biasa disebut e-learning menjadikan para guru terampil menggunakan e-learning dengan siswanya. Disisi yang lain dengan proses pembelajaran elearning yang disimulasikan dengan para guru terlihat sangat senang dan menarik sehingga dapat termotivasi.

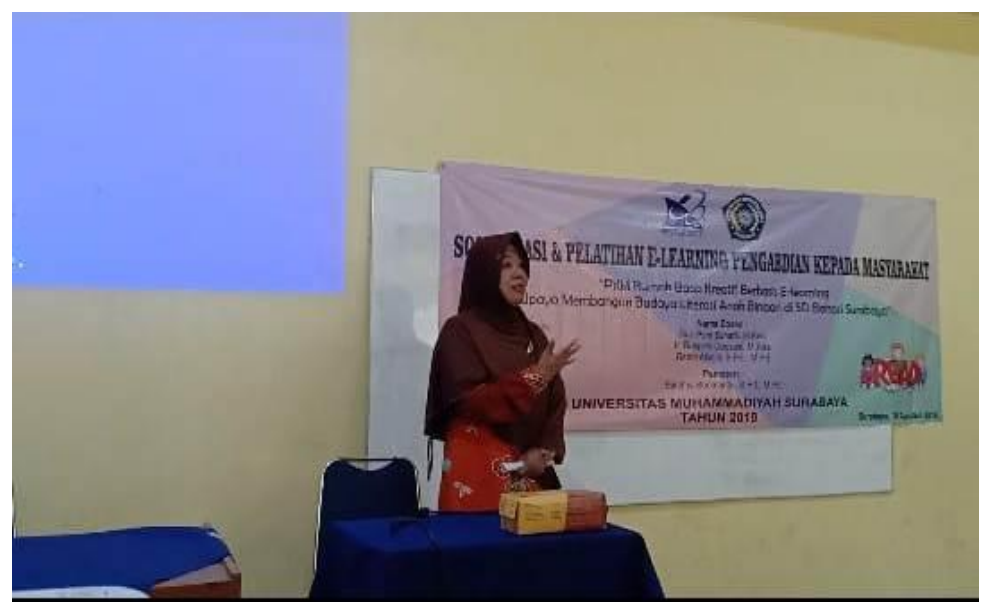

Gambar 1. Sosialisasi E-learning terhadap Mitra 
Ketua tim menyampaikan pentingnya menggunakan teknologi informasi di era sekarang tanpa terkecuali. Khususnya pendidikan harus ada upaya yang harus dilakukan untuk meningkatkan kualitas pendidikan sehingga menjadi pendidikan yang unggul dan berdaya saing. SD Muhammadiyah 9 Bahari Surabaya sudah ingin memulai ikut andil dalam perubahan yang terus berlanjut dengan memulai proses pembelajaran menggunakan $e$ learning bersama tim pelaksana program kemitraan masyarakat. Ketua tim mempresentasikan tujuan utama pembelajaran e-learning sebagai salah satu upaya memberikan alternatif pembelajaran yang menyenangkan.

2. Workshoop Implementasikan e-learning Tahap Satu

Pada pelaksanaan pelatihan e-learning di falitasi oleh tim pelaksana dan dijelaskan langsung oleh pemateri pelatihan. Pada awal pelatihan ini memberikan pemahaman secara mendasar untuk menjadikan para guru memahami menggunakan prosedur e-learning secara utuh dengan memberikan arahan memasukkan akun pribadi untuk masuk ke e-learning. Guru sebagai salah satu fasilitator harus mampu menfasilisasi siswanya dengan menyiapkan berbagai media pembelajaran yang dapat digunakan saat proses pembeajaran berlangsung
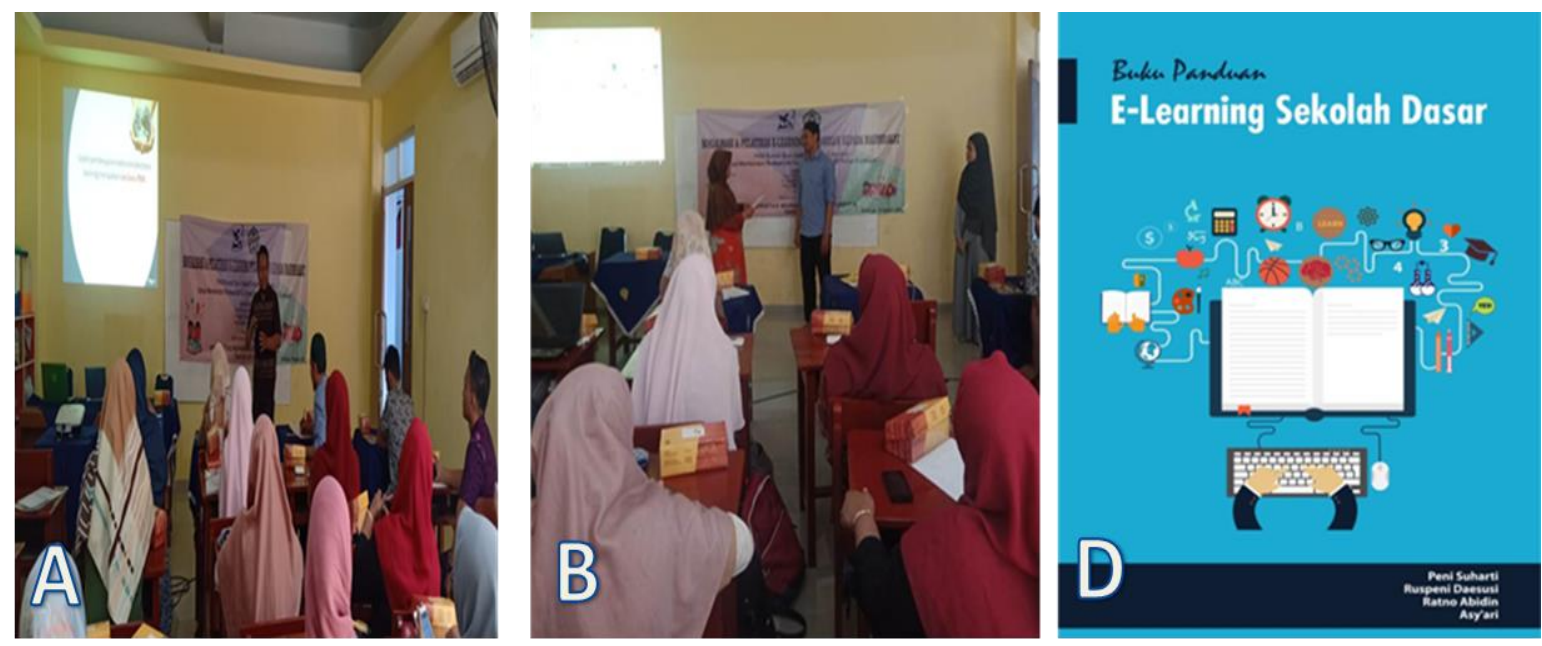

Gambar 2. A. Penyampaian materi E-learning kepada Para Guru SDM 9 Surabaya, B. penyerahan buku panduan dan text book, C. Buku Panduan e-learning Sekolah Dasar

Untuk menunjang kegiatan workshoop guru dipasilitasi dengan buku panduan penggunan e-learning, dengan tujuan agar dalam proses pelatihan dan pendampingan guru lebih mudah dan cepat memahmi. Selain itu mitra juga diberikan buku-buku bacaan berupa text book dan e-book dan hal ini sebagai upaya membangun budaya literasi. Karena membangun budaya literasi harus dipaksa untuk menjadikan mereka gemar membaca. Sehingga dengan membaca para guru dan anak binaan mampu menjadikan mereka berdaya dan banyak pemahaman. Ketika para guru dan anak binaan banyak pemahaman maka mereka dapat membangun kreatifitasnya dan mereka akan menjadi pribadi yang inovatif.

3. Pendampingan Guru Dalam Mengoprasikan E-Learning tahap satu

Sebagai upaya cakap teknologi dan menumbuhkan budaya literasi bagi para guru dan anak binaan maka dilakukan pendampingan secara inten dan memberikan pemahan ketika ada kesalahan yang dialaminya di SD Muhammadiyah 9 Bahari Surabaya. Dengan semangat guru mengikuti pendampingan e-learning dan menerapkan dalam proses pembelajaran dengan tujuan memberikan alternatif pembelajaran yang menyenangkan. Kemudian di lingkup SD yang menjadi sasaran dalam mengikuti e-learning ada ketentuan umur yaitu: kelas 4 sampai 6. Karena dengan kelas itu sudah siap dan dapat mengikuti program elearning. 


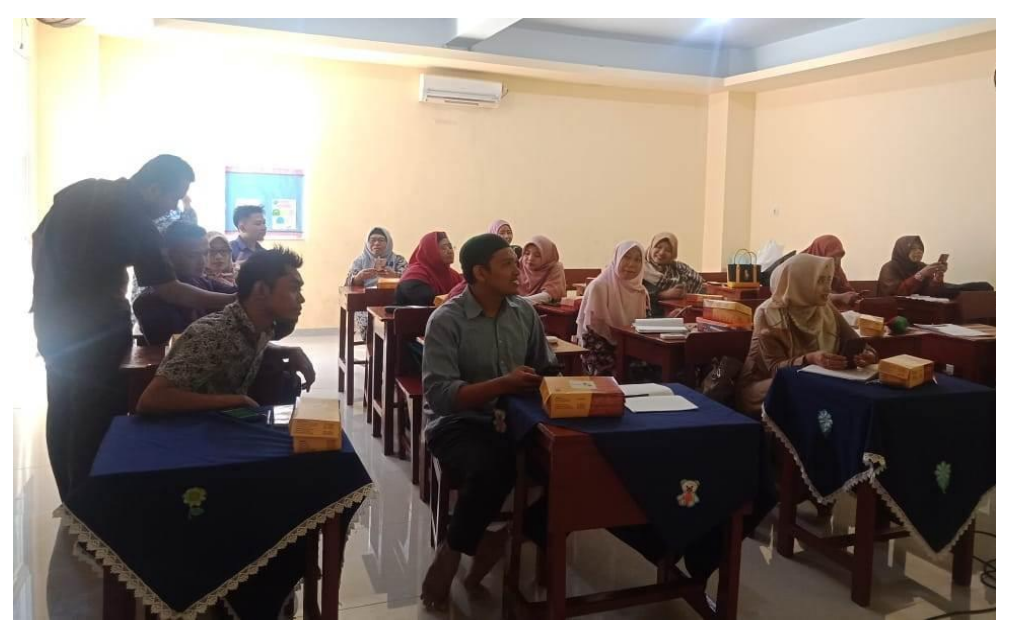

Gambar 3. Pendampingan E-Learning PKM Guru SDM 9 Surabaya

\section{Pelatihan Implementasi E-Learning}

Pada pelaksanaan pelatihan yang ke dua yang langsung di fasilitasi oleh tim pelaksana dan di jelaskan langsung oleh pemateri. sebagai upaya memberikan penambahan pemahaman secara utuh tentang point-point penting didalam elearning salah satu contoh yaitu schoology yang diberiakan kepada peserta dan diberikan cara mengoprasikan mulai dari awal sampai pada bagaimana memasukkan pembelajaran, penugasan/kuis, penilaian dan lain-lain. Program e-learning tentu banyak macamnya namun yang diajarkan kepada para guru SD Muhammadiyah 9 Bahari Surabaya yaitu schoology dari mulai secara teoritis sampai pada bagaimana pada mengimplementasikan program e-learning dengan mudah. Karena dengan percepatan teknologi yang semakin canggih tentu menggunakan e-learning adalah bagaimana mengikuti perkembangannya, walaupun semua guru tidak detail memahami perkembangan teknologi secara keseluruhan.

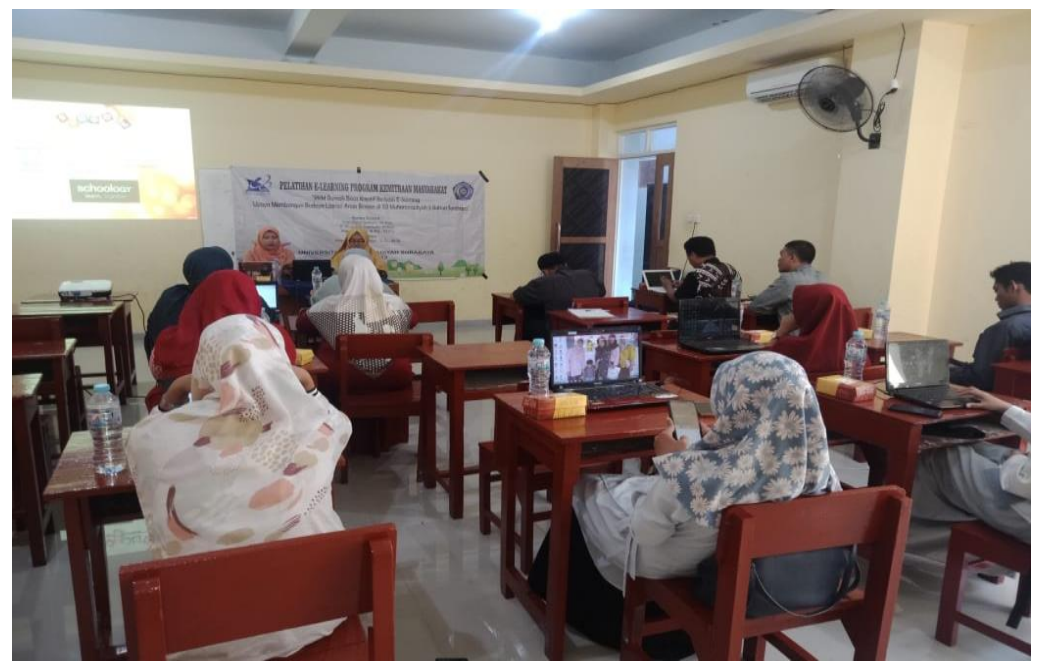

Gambar 4. Materi E-learning kedua kepada Para Guru SDM 9 Surabaya

5. Pendampingan guru dalam mengoprasikan e-learning

Upaya cakap teknologi dan menumbuhkan budaya literasi bagi para guru dan anak binaan dilakukan pendampingan secara masif dalam rangkan memberikan pembiasaan menguprasikan teknologi yang merupakan bagian dari media pembelajaran di SD Muhammadiyah 9 Bahari Surabaya. Karena dengan pendampingan tim pelaksana memperdayakan para guru karena mereka menjadi ujung tombak cerdas dan cakapnya seorang anak. Dalam pendampingan ini memberiakan kemudahan kepada guru untuk belajar menggunakan pembelajaran e-learning secara untuh. Karana ada sebagian guru yang masih 
belum mampu mengoprasikan teknologi sehingga dengan adanya pendampingan PKM para guru sangat antosias belajar menggunakan e-learning.

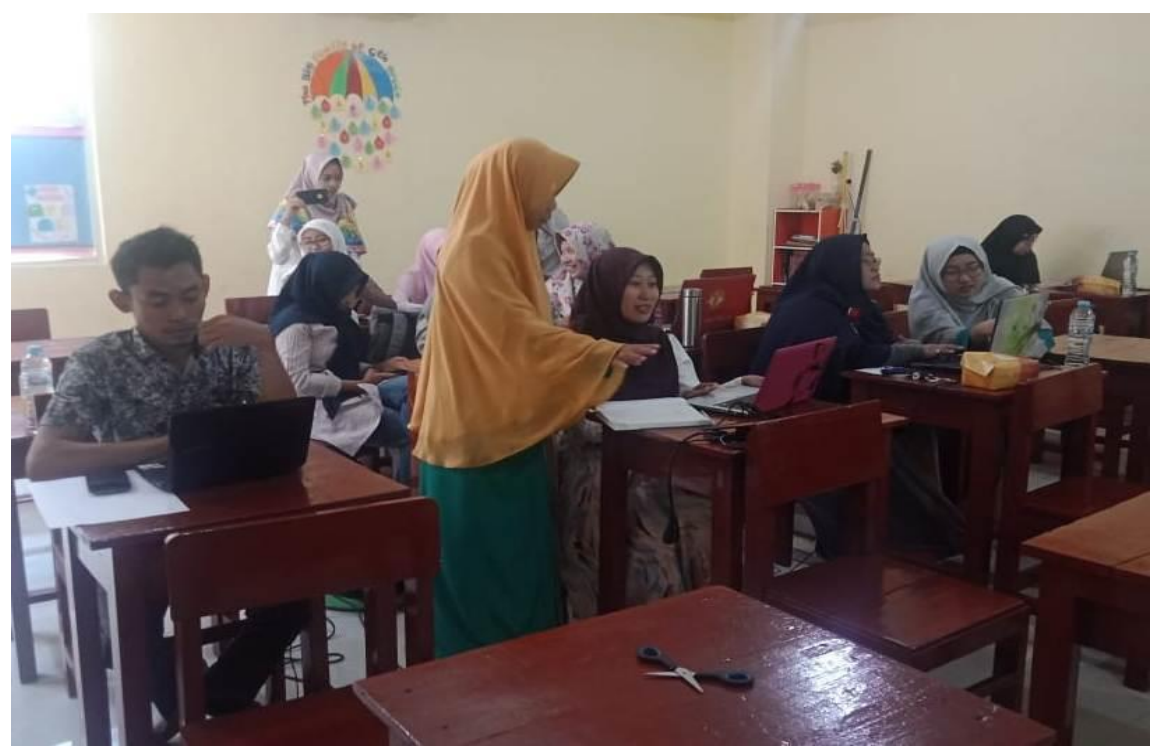

Gambar 5. Pendampingan E-Learning PKM Guru SDM 9 Surabaya

6. Wokshop E-learning di SD Muhammadyah 9 Bahari Surabaya

Dalam acara ini menjadikan guru tidak sekedar paham teori teori tentang e-learning tapi para guru dan anak binaan dapat mengoprasikan secara langsung bagaimana joint antara pendidik dan peserta didik, mengerjakan tugas secara online dan lain-lain yang merupakan bagian dari e-learning (schoology). Pada acara workshop ini guru mencoba memberikan pembelajaran kepada peserta dengan beberapa dokumen yang di upload kemudiam ditanggapi oleh siswa dan dikerjakan kerjakan oleh siswa beberapa tugas yang diperintahkan oleh guru dalam elearning. Guru yang semula sulit menggunakan e-learning maka dengan adanya acara workshop melalui program pengabdian kepada masyarakat ini para guru mampu menggunakan media pembelajaran e-learning secara baik dan benar.

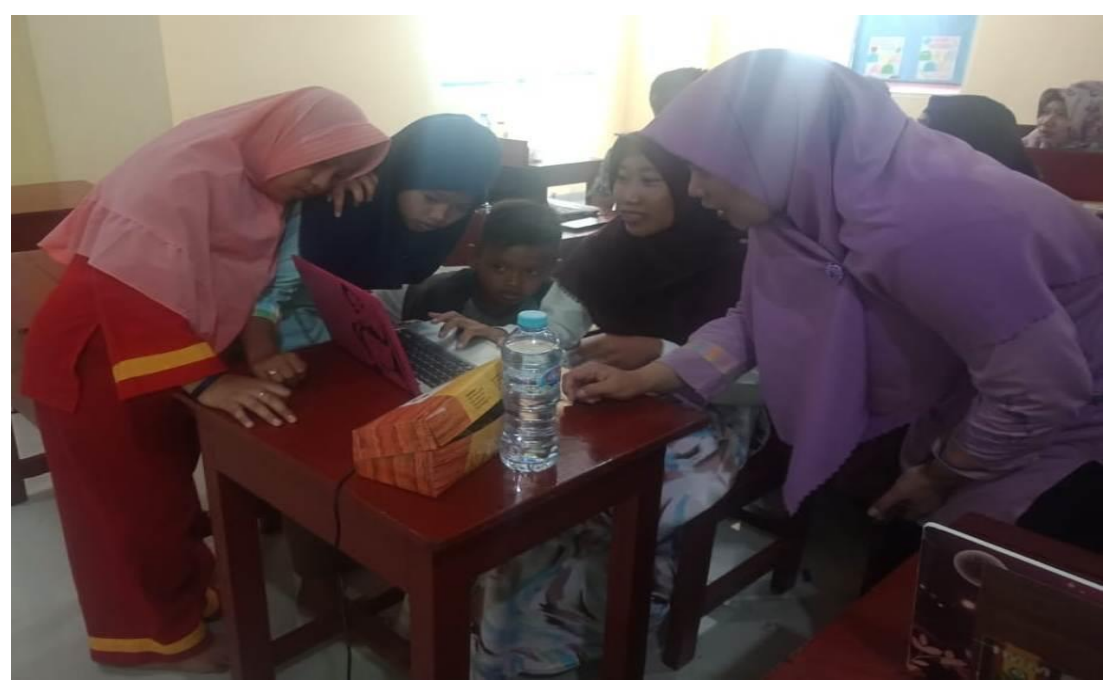

Gambar 6. Melatih para guru dan anak binaan menggunakan e learning sebagai media belajar dan mengejar

7. Evaluasi

Pada komponen evaluasi pelaksanaan pembelajaran e-learning SD Muhammadiyah 9 Surabaya yang mendasar yaitu guru melaksanakan penilaian dan melihat keaktifan siswa dalam pembelajaran e-learning, serta guru memberikan tugas melalui e-learning. Hal tersebut 
belum dilaksanakan secara optimal oleh semua guru dalam setiap kegiatan pembelajarannya. Rekomendasi untuk evaluasi pelaksanaan pembelajaran e-learning yaitu dilaksanakan secara terus-menerus samapai pada bagaimana guru dan pesrta didik bisa join dalam pembelajaran e-learning. Kesiapan pelaksanaan pembelajaran dengan $e$-learning dapat dilihat dari tiga dimensi, yaitu motivasi untuk menggunakan $e$-learning, kompetensi atau kemampuan yang cukup untuk mengelola dan mengikuti pembelajaran e-learning, dan sumberdaya yang meliputi fasilitas, akses, dan teknologi yang memadai. Keberhasilan pembelajaran dengan media e-learning berhubungan dengan usaha yang konsisten dan terintegrasi dari siswa, sekolah, guru sebagai fasilitator, staf penunjang, dan administrator (Yazdi, 2012).

\section{KESIMPULAN}

Kegiatan pengabdian kepada masyarakat yang melibatkan guru SD Muhammadiyah 9 Surabaya telah berjalan dengan baik sesuai dengan perencanaan, terbukti dengan tercapainya kemampuan guru dalam memahami dan menggunakan e-learning sebagai media pembelajaran dalam proses mengajar yang di implementasikan pada kelas 4,5 dan 6 . Sehingga dengan pembelajaran e-learning ini memberikan alternatif pembelajaran yang menyenangkan kepada siswa.

\section{SARAN}

Kegiatan pelatihan guru-guru tentang pembelajaran berbasis e-learning masih terbatas pada guru-guru kelas 2.5 dam 6. Sehingga kedepanya perlu dilakukan inovasi yang lebih baik agar guru-guru kelas 1,2 dan 3 diberikan pelatihan dan pendampingan tentang pembelajaran e-learning sesuai dengan perkembangan kognitif siswa kelas yang dajarkannya.

\section{UCAPAN TERIMA KASIH}

Proram pengabdian kepada masyarakat ini dapat berjalalan sesuai dengan waktu yang ditentukan. Maka kami tim pelaksana menyampaikan terimaksih kepada Kemenristekdikti yang telah memberikan dana hibah PKM kepada tim.

\section{DAFTAR PUSTAKA}

Aztry, A. (2016 ). Upaya Menumbuh Kembangkan budaya iterasi Melalui Rumah Baca Taqwa. The 1st International Conference on Lnguage, Literature and Teaching (pp. 12). Bandung: UPI

Daryanto, S. (2018). Dampak Perkembangan Teknologi Informasi dan Komunikasi. jurnal SIMBOLIKA, 4 (1) , 63. DOI: 10.31289/simbollika.v4i1.1474

Diana, A. (2018). Komponen Pengembangan E-Learning. Jurnal Pembelajaran Inovatif (JPI) 1(1) 58-65. journal.unj.ac.id/unj/index.php/jpi/article/download/6113/4433

Ngafifi, M. (2014). Kemajuan Teknologi dan Pola Hidup Manusia. Jurnal Pembangunan Pendidikan: Fondasi dan Aplikasi. 2(1) 33-47. https://doi.org/10.21831/jppfa.v2i1.2616

Mansyur M. (2019) Gempusta: Upaya Meningkatkan Minat Baca. Disajikan pada Seminar Nasional Bahasa dan Sastra Indonesia II (Narasi II) Himaprodi FBS UNM 2019 Tanggal 16-17 November 2019, Menara Phinisi UNM Makassar. https://www.researchgate.net/publication/337671871_Gempusta_Upaya_Meningkatkan Minat_Baca

Rosini, R., \& Nurningsih, S. (2018). Pemanfaatan Media Sosial untuk Pencarian dan Komunikasi Informasi Kesehatan. Berkala Ilmu Perpustakaan dan Informasi. 14(2). 226-237. https://doi.org/10.22146/bip.33844

Siswati (2010) Minat Membaca Pada Mahasiswa (Studi Deskriptif Pada Mahasiswa Fakultas Psikologi Undip Semester I) Jurnal Psikologi Undip 8(2)124-134. DOI: 10.14710/jpu.8.2.124-134 
Hanum, S. N. (2013). Keefektifan E-Learning Sebagai Media Pembelajaran . Jurnal Pendidikan Vokasi, 3(1) 90-102 DOI: https://doi.org/10.21831/jpv.v3i1.1584

Hutapea E. (2019) 3 Hal Ini Jadi Penyebab Rendahnya Minat Baca Anak Indonesia. Kompas.com. 10/09/2019https://edukasi.kompas.com/read/2019/09/10/15225581/3hal-ini-jadi-penyebab-rendahnya-minat-baca-anak-indonesia?page=all.

Meliza M., Adnan., \& Safiah I. (2016). Strategi Guru Dalam Meningkatkan Kemampuan Membaca Pada Siswa Kelas Rendah Gugus Inti Kecamatan Peudada Kabupaten Bireuen. Jurnal Ilmiah Pendidikan Guru Sekolah Dasar FKIP Unsyiah. 1(2) 26-36 Oktober, http://www.jim.unsyiah.ac.id/pgsd/article/view/1801

Yazdi, M. (2012). E-Learning Sebagai Media Pembelajaran . Jurnal Ilmiah Foristek 2(1), 143-152. http://jurnal.untad.ac.id/jurnal/index.php/FORISTEK/article/view/665 